\title{
y-Valerolactone-Extracted Lignin to Porous Carbon Materials
}

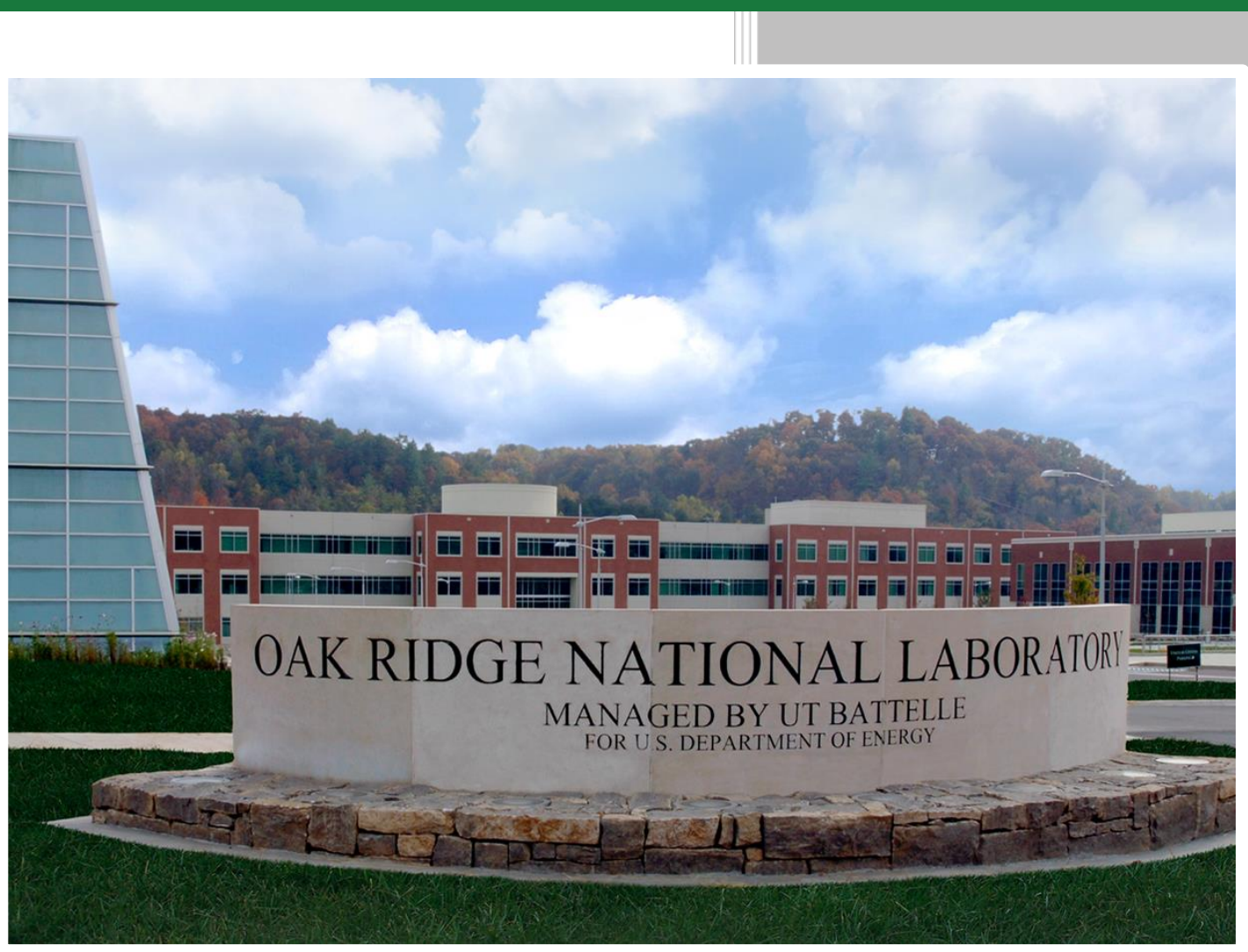

CRADA final report for CRADA number NFE-16-06138

Approved for public release. Distribution is unlimited.
Hoi Chun Ho Ngoc A. Nguyen Kelly M. Meek David M. Alonso Sikander H. Hakim Jeffrey J. Fornero Amit K. Naskar July, 2018 


\section{DOCUMENT AVAILABILITY}

Reports produced after January 1, 1996, are generally available free via US Department of Energy (DOE) SciTech Connect.

Website http://www.osti.gov/scitech/

Reports produced before January 1, 1996, may be purchased by members of the public from the following source:

National Technical Information Service

5285 Port Royal Road

Springfield, VA 22161

Telephone 703-605-6000 (1-800-553-6847)

TDD 703-487-4639

Fax 703-605-6900

E-mail info@ntis.gov

Website http://www.ntis.gov/help/ordermethods.aspx

Reports are available to DOE employees, DOE contractors, Energy Technology Data Exchange representatives, and International Nuclear Information System representatives from the following source:

Office of Scientific and Technical Information

PO Box 62

Oak Ridge, TN 37831

Telephone 865-576-8401

Fax 865-576-5728

E-mail reports@osti.gov

Website http://www.osti.gov/contact.html

This report was prepared as an account of work sponsored by an agency of the United States Government. Neither the United States Government nor any agency thereof, nor any of their employees, makes any warranty, express or implied, or assumes any legal liability or responsibility for the accuracy, completeness, or usefulness of any information, apparatus, product, or process disclosed, or represents that its use would not infringe privately owned rights. Reference herein to any specific commercial product, process, or service by trade name, trademark, manufacturer, or otherwise, does not necessarily constitute or imply its endorsement, recommendation, or favoring by the United States Government or any agency thereof. The views and opinions of authors expressed herein do not necessarily state or reflect those of the United States Government or any agency thereof. 
Advanced Manufacturing Office Materials Science and Technology Division

$\gamma$-Valerolactone-Extracted Lignin to Porous Carbon Materials

Hoi Chun Ho

Ngoc A. Nguyen

Kelly M. Meek

Amit K. Naskar

Oak Ridge National Laboratory

David M. Alonso

Sikander H. Hakim

Jeffrey J. Fornero

Glucan Biorenewables, LLC.

Date Published:

May 11, 2018

\author{
Prepared by \\ OAK RIDGE NATIONAL LABORATORY \\ Oak Ridge, Tennessee 37831-6283 \\ managed by \\ UT-BATTELLE, LLC \\ for the \\ US DEPARTMENT OF ENERGY \\ under contract DE-AC05-00OR22725
}

Approved for

Public Release 


\section{Table of Contents}

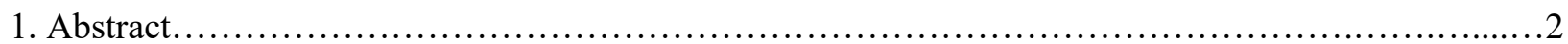

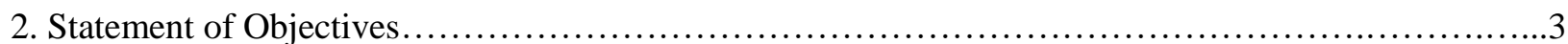

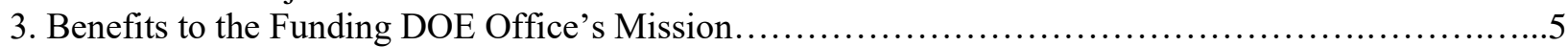

4. Technical Discussion of Work Performed by All Parties......................................... 6

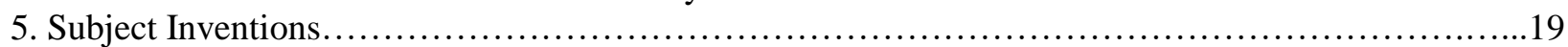

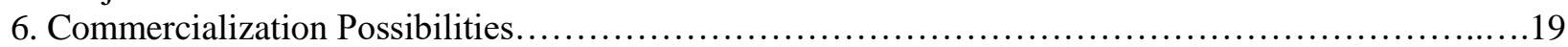

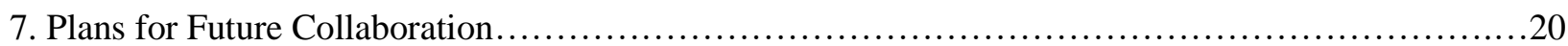

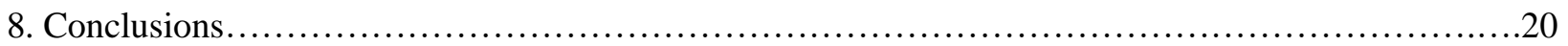




\section{ABSTRACT}

Synthesis of multiphase materials from lignin, a biorefinery coproduct, offers limited success due to the inherent difficulty in controlling dispersion of these renewable hyperbranched macromolecules in the product or its intermediates. Effective use of the chemically reactive functionalities in lignin, however, enables tuning morphologies of the materials. Here, we bind a lignin oligomer with a rubbery macromolecule followed by thermal crosslinking to form a carbon precursor with phase contrasted morphology at submicron scale. The solvent-free mixing is conducted in a high-shear melt-mixer. With this, the carbon precursor is further modified with potassium hydroxide for a single-step carbonization to yield activated carbon with tunable pore structure. A typical precursor with $90 \%$ lignin yields porous carbon with $2120 \mathrm{~m}^{2} / \mathrm{g}$ surface area and a supercapacitor with $215 \mathrm{~F} / \mathrm{g}$ capacitance. The results show a simple route towards manufacturing carbon-based energy-storage materials, eliminating the need for conventional template-synthesis. 


\section{STATEMENT OF OBJECTIVES}

The Small Business Voucher Participant (Glucan Biorenewables) is a seed-stage company that converts biomass to bio-fuels, intermediates, specialty chemicals, and advanced biomaterials. The technology uses the solvent gamma-valerolactone (GVL) to fractionate biomass into a soluble lignin and hemicellulose fraction while the cellulose remains as a solid that can be physically separated. The lignin is precipitated as a product from the hemicellulose and the hemicellulose is readily converted to furfural. The GVL is biomass-derived, non-toxic, can be cleaned and recycled. The participant's technology cleanly fractionates, then upgrades the three core components of biomass; cellulose, hemicellulose, and lignin. Using no enzymes or intermediate separations, three distinct high yielding revenue streams are produced with overall yields $>75 \%$ to enable low cost production. Patent protected, this technology performs hydrolysis reactions $100 \mathrm{X}$ and dehydration reactions $30 \mathrm{X}$ faster than competing aqueous processes. The participant aims to capture a significant share of the growing global renewable products market, particularly, in renewable carbon for energy storage applications. The ability to valorize the lignin will also enable low-cost biofuel production.

Biomass conversion to fuel and chemicals is one of the challenges to reduce the dependence on fossil fuel resources. While great success has been achieved using the cellulose and the hemicellulose fraction, ${ }^{[1]}$ lignin remains underutilize ${ }^{[2]}$ and many researchers see its valorization as the key to improving the economics of biomass conversions to levels competitive with petroleum. Recently a new organosolv fractionation method using $\gamma$-valerolactone (GVL) has been reported. ${ }^{[3]}$ This method maximizes the conversion of the lignocellulosic biomass to high value products ( $>80 \%$ of the original wood mass to product) and produces a high purity lignin, with a significant amount of $\beta-\mathrm{O}-4$ ' linkages that can be used as a high value coproduct, like lignin-derived carbon. ${ }^{[4]}$ Although major development effort has gone into controlling lignin carbon's morphology, the scientific community still struggles. ${ }^{[5]}$ This is likely due to the fact that lignin is a highly branched and complex polymer. ${ }^{[2]}$ Nevertheless, the plentiful functional groups $^{[6]}$ on lignin make it amenable for chemical reactions. ${ }^{[2 a]}$

The ORNL team previously learned that thermal stabilization in air can crosslink lignin itself or with acrylonitrile-butadiene rubber (NBR), giving different thermomechanical properties of the lignin-NBR adducts, hinting to a pathway for better control of morphology. ${ }^{[7]}$ Covalent bonds like ether linkages within lignin are thermally sensitive ${ }^{[8]}$ especially when they are next to phenolic rings, due to the resonance effects with the $\Pi$ electron conjugation. As a good radical scavenger ${ }^{[9]}$ any free radicals generated from the thermally sensitive linkages during stabilization can then crosslink with reactive sites on other lignin molecules resulting in a molecular weight change. ${ }^{[10]}$ Concurrently, lignin radicals can also attack the unsaturated carbon-carbon double bonds $(\mathrm{C}=\mathrm{C})$ on NBR, in turn, crosslinking with NBR. ${ }^{[7,11]}$ By utilizing lignin crosslinking with different polymers, novel green polymer products can be designed. Akato et al. reported use of $10 \%$ polyethylene oxide (PEO) in lignin to reduce lignin domain sizes in acrylonitrile-butadiene-styrene (ABS) polymer that helps to retain mechanical properties at $30 \%$ lignin loading. Bova et al. successfully produced high performing NBR-lignin blends consisting of small amount of low cost additives like PEO, carbon black, etc. and having tensile strength up to $25 \mathrm{MPa}$ and failure strain up to $140 \%$. Using temperature induced nanoscale-dispersion of lignin, Tran et al. synthesized an NBR blend with outstanding recyclability and yield stress of up to $45 \mathrm{MPa}$. Similarly, Nguyen et al. made an NBR-lignin blend and demonstrated its use for shape memory and sensor applications.

Based on lessons learned from our prior work with compatibility of lignin-acrylonitrile containing copolymers (NBR and ABS), herein, by doping with small quantity of NBR (10 wt. \%) and thermally crosslinking lignin, we could tailor the degree of NBR dispersion in the lignin blends. This enabled us to tune the morphology of the lignin-derived carbon after high temperature carbonization. Lignin oligomers, like phenolic resins are well-known carbon precursors. Synthesis of mesoporous carbon from these 
precursors usually require soft-template synthesis using block copolymers such as Pluronic as a templating agent. ${ }^{[5 b, 12]}$ In this process, a carbon precursor (e.g., phenolic resin) is mixed with Pluronic and crosslinked in solution to form a mesoscale, phase separated morphology. While retaining such morphology in a crosslinked polymer gel, the solvent is evaporated very slowly to produce a pyrolyzable crosslinked precursor monolith. For example, previous studies involving lignin carbon's morphological control used a Pluronic surfactant with tetrahydrofuran and hydrochloric acid $(\mathrm{HCl})$ mix for templating an $\mathrm{HCl}$ treated lignin prior to carbonization and activation. ${ }^{[12]}$ In another case, a lignin-cellulose mix was dissolved in a chloroform-water mixture in the presence of sodium dodecylbenzenesulfonate prior to precipitation in acetone, drying, and carbonization. ${ }^{[5 b]}$ In this work we report mesoporous phaseseparated morphology of lignin by a melt-based synthesis route without use of solvent and its slow evaporation. A solvent-free, fast, extrusion-type processing of lignin to yield a porous carbon precursor is the key innovation here.

To the best of our knowledge, this is the first attempt towards designing a lignin carbon morphology without the use of any solvent or block copolymer templating agents. To maximize the utilization of lignin as an industrial co-product, a 90\% lignin loading was used across all samples. This is so far the highest lignin loading among many lignin-polymer prior art which have lignin loading anywhere between 10 to $60 \% .^{[7,11,13]}$ Using this simple design principle, we aimed to synthesize a better porous carbon from lignin and to improve its performance as supercapacitor electrode. 


\section{BENEFITS TO THE FUNDING DOE OFFICE'S MISSION}

Small businesses in the clean energy sector are working with the Department of Energy's national laboratories. As part of Energy Efficiency and Renewable Energy's (EERE) National Laboratory Impact Initiative, the program aims to help small businesses bring next generation clean energy technologies to the market faster by enabling them to access expertise and specialized equipment at national laboratories.

Oak Ridge National Laboratory (ORNL) assisted Glucan Biorenewables in performing a qualifying step to advance its unique gamma-valerolactone-derived lignin, toward a commercial functional carbon material. The research advances the development of the lignin isolation process targeted towards production of lignin with specific traits. With this lignin, the research developed solvent-free processing to manufacture a porous renewable carbon applicable for energy storage and environmental remediation. 


\section{TECHNICAL DISCUSSION OF WORK PERFORMED BY ALL PARTIES}

Glucan Biorenewables, LLC extracted lignin from hardwood biomass (Birch) using gamma-valerolactone solvent. To confirm the possibility of crosslinking reactions within this renewable lignin (GLB-lignin), 2D nuclear magnetic resonance spectroscopy was conducted to determine the availability of thermally sensitive linkages (see Figure 1-3, Table 1). Syringyl propane units (substructures S and S') were observed at relatively high concentrations, while guaiacyl propane unit (substructure G) and phydroxyphenyl propane units (substructure $H$ ) were observed at lower concentrations. Within the structural units, GLB lignin contains significant $\beta$-O-4' linkages (substructure A), $\beta-5$ ' linkages (substructure $\mathrm{B}$ ), and $\beta-\beta$ linkages (substructure $\mathrm{C}$ ). The presence of these thermally reactive linkages, particularly the $\beta$-O-4' linkages, gives the possibility of free radical formation for cross-linking reactions and macromolecular rearrangements. The current study relies on these reactive sites for tuning the ligninderived carbon morphology and functionality.

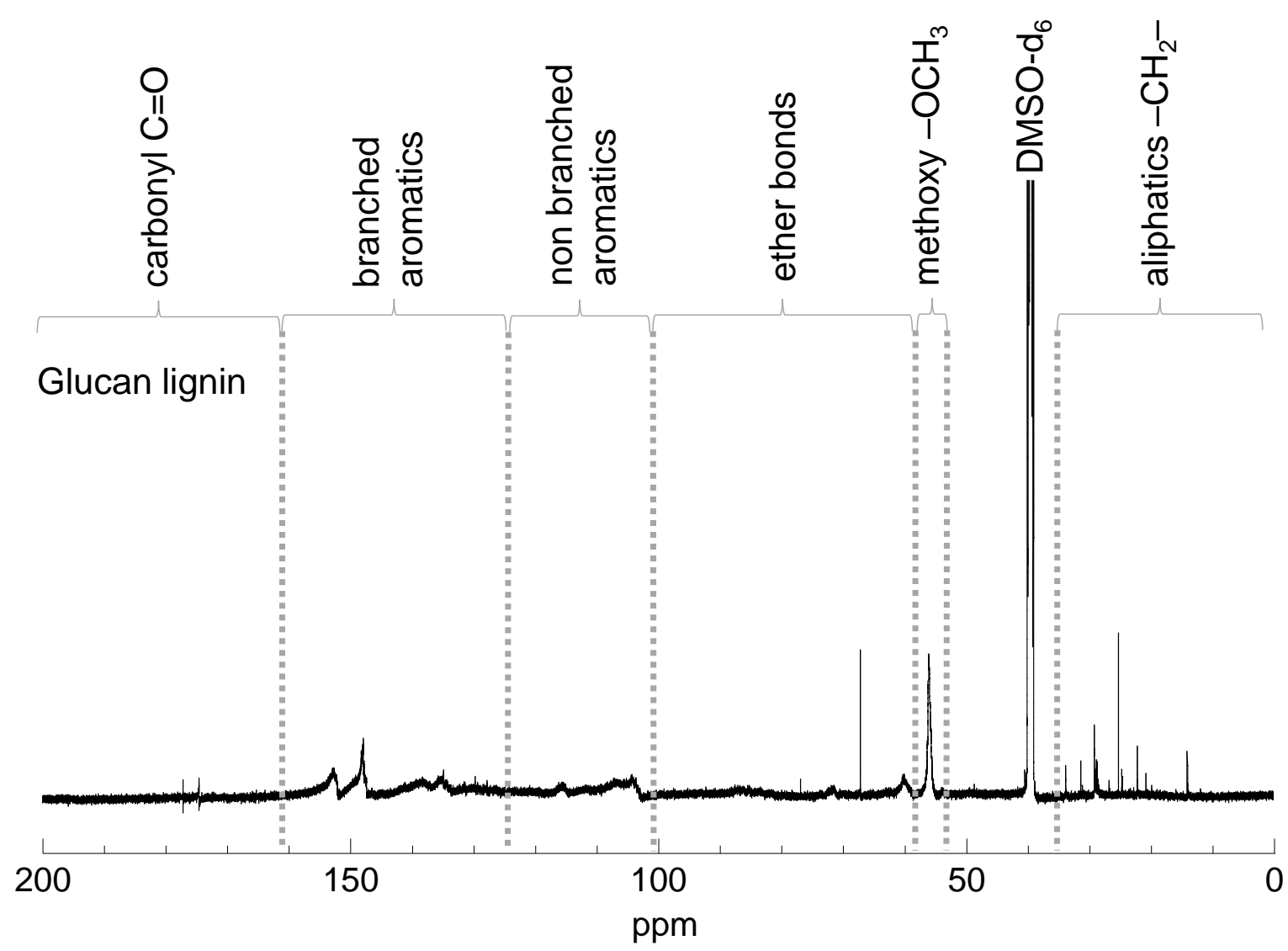

Figure $1 .{ }^{13} \mathrm{C}$ NMR spectra of GLB lignin. 


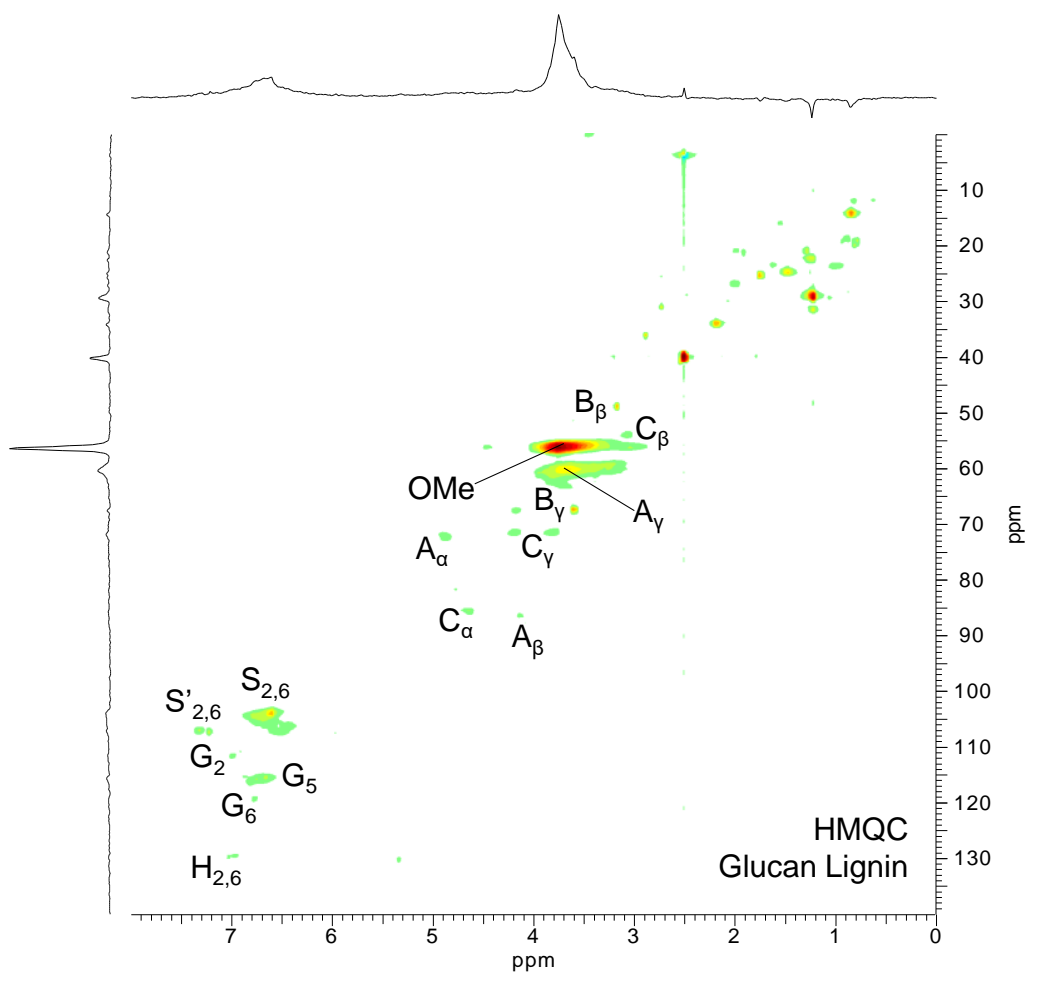

Figure 2. HMQC spectrum of GLB lignin. Assigned lignin substructures are in Figure 3.
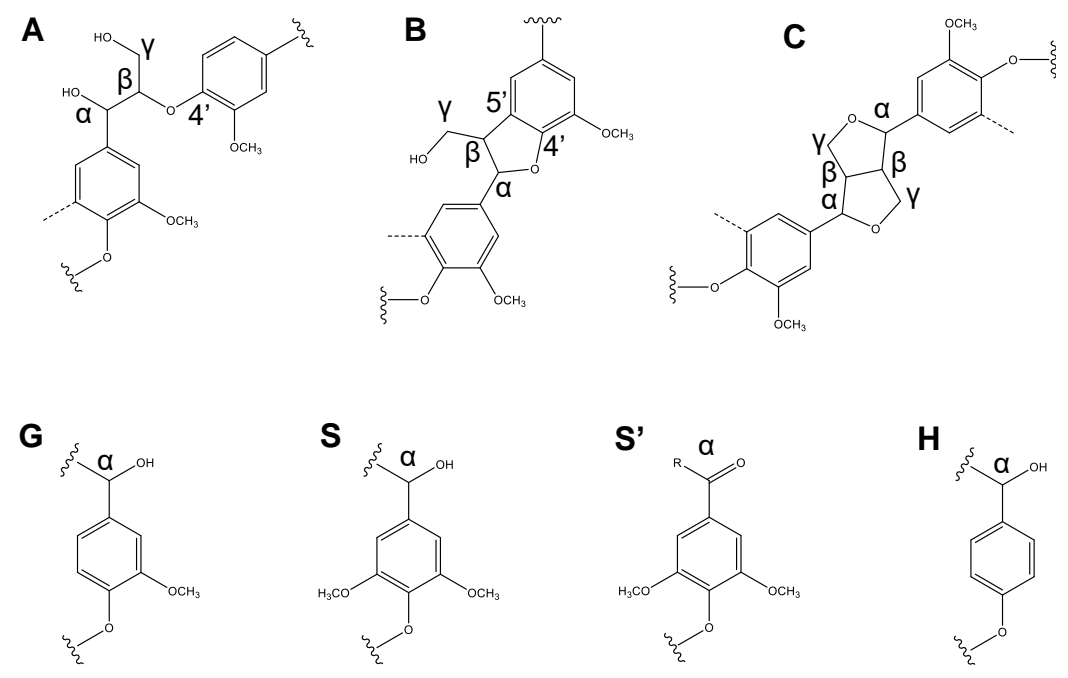

Figure 3. Lignin substructures detected by HMQC. (A) $\beta-O-4^{\prime}$; (B) $\beta-5^{\prime}$ ' (phenylcoumaran structure); (C) $\beta$ - $\beta$ ' (resinol structure); (G) guaiacylpropane unit; (S) syringyl propane unit; (S') syringyl propane unit with carbonyl at $\mathrm{C}_{\alpha} ;(\mathrm{H}) p$-hydroxyphenolpropane unit. 
Table 1. Signal Assignment in the ${ }^{13} \mathrm{C}$ NMR spectrum of GLB Lignin.

\begin{tabular}{|c|c|c|}
\hline $\begin{array}{l}\text { Range } \\
\text { (ppm) }\end{array}$ & Assignment & $\begin{array}{l}\text { Amount } \\
\text { (per } \\
100 \mathrm{Ar} \text { ) }\end{array}$ \\
\hline $\begin{array}{l}162- \\
142\end{array}$ & $\mathrm{C}_{\mathrm{AR}-\mathrm{O}}$ & 192 \\
\hline $\begin{array}{l}142- \\
125\end{array}$ & $\mathrm{C}_{\mathrm{AR}-\mathrm{C}}$ & 208 \\
\hline $\begin{array}{l}125- \\
102\end{array}$ & $\mathrm{C}_{\text {AR-H }}$ & 212 \\
\hline $90-77$ & $\begin{array}{c}\text { Alk-O-Ar, } \\
\text { a-O-Alk }\end{array}$ & 53 \\
\hline $77-65$ & $\begin{array}{c}\mathrm{y}-\mathrm{O}-\mathrm{Alk} \\
\mathrm{OH} \\
\mathrm{sec}\end{array}$ & 30 \\
\hline $65-58$ & $\mathrm{OH}_{\text {prim }}$ & 52 \\
\hline $58-54$ & $\mathrm{OMe}$ & 122 \\
\hline $54-52$ & $\mathrm{C}_{\beta-\beta,}, \mathrm{C}_{\beta-5}$ & 7 \\
\hline
\end{tabular}

In our previous studies, crosslinking lignin with rubbers was accomplished by simple melt mixing that resulted in the observation of small (nanometer to micrometer scale) lignin aggregates dispersed within the rubber matrix. The lignin aggregates were described as "island in the sea" and "spaghetti and meatball" when observed under electron microscopes. ${ }^{[7,11,13]}$ With this in mind, we carbonized a 10 wt.\% NBR doped lignin and observed rough macroporous structures under scanning electron microscope (Figure $4 \mathrm{a}-\mathrm{c}$ ), that are independent of stabilization duration. The investigated samples, namely GLB-D, 1-GLB-D, and 6-GLB-D, are the carbonized lignin NBR composites with no stabilization, one-hour stabilization, and six-hour stabilization, respectively. Notably, the "island in the sea" and "spaghetti and meatball" type morphology was retained through the carbonization and activation process. In contrast, all undoped (without NBR) lignin carbon samples show relatively less porous surfaces (Figure $4 \mathrm{~d}$-f), resulting from the lack of NBR dispersion. The GLB, 1-GLB, and 6-GLB samples are carbonized undoped lignin with no stabilization, one-hour stabilization, and six-hours stabilization, respectively. It is remarkable that even at as low as $10 \%$ NBR doping, as oppose to the $60 \%$ NBR loading in our previous studies ${ }^{[11,13]}$ carbon morphology with submicron-scale pore structures can be produced. 

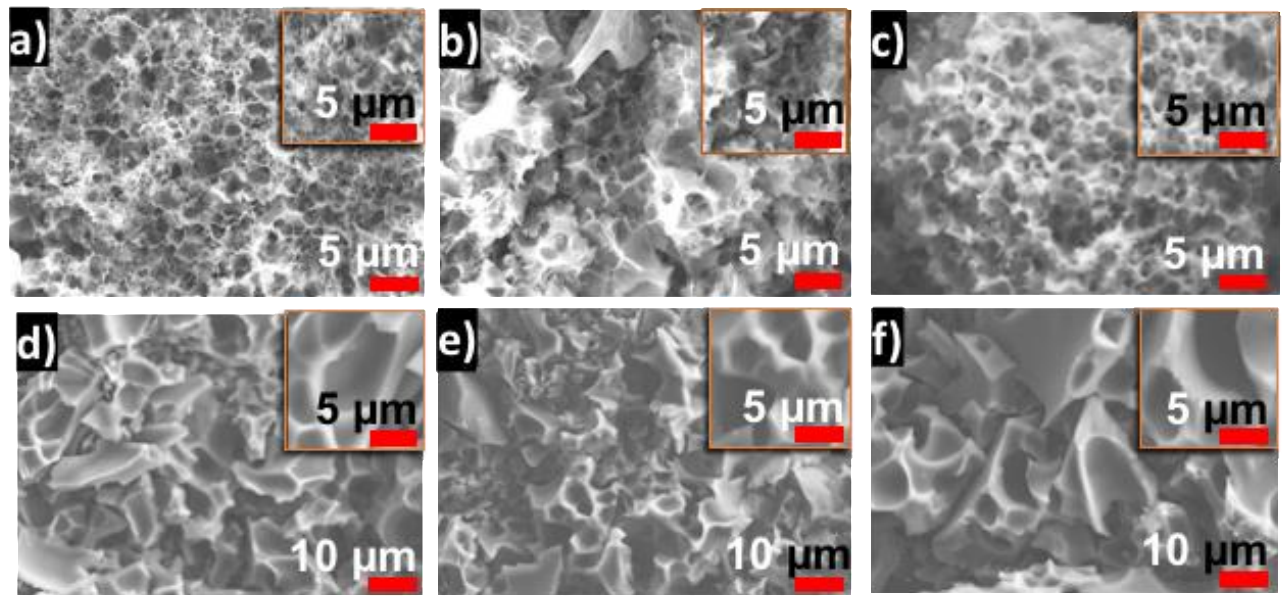

Figure 4. Scanning electron microscope images of carbonized GLB lignin and its rubber composites. a)-c) Doped lignin-derived carbon from composition with $90 \%$ lignin and $10 \%$ NBR. d)-f) Undoped lignin-derived carbon, i.e., carbon from 100\% lignin. Left to right are samples with no stabilization time, one-hour stabilization, and six-hour stabilization.

It is known that the porosity of activated carbon produced from polymer precursors like lignin can be controlled by varying the molecular weight of the precursor. ${ }^{[4 b, 14]}$ By stabilizing lignin and lignin NBR composite in air, their degree of crosslinking was controlled, and thus the morphology of the final activated carbon was controlled.

The first hint of success in controlling the degree of crosslinking via stabilization in air came as the color changed in lignin samples from a light to dark brown powder (see inset of Figure 5c). A more definite way to confirm a change in molecular weight by size exclusion chromatography (SEC) could not be accomplished due to lack of solubility of highly crosslinked samples. For example, SEC can only be performed with GLB and 1-GLB carbon precursors (P-GLB and P-1-GLB). The number average molecular weights $\left(\mathrm{M}_{\mathrm{n}}\right)$ of P-GLB and P-1-GLB are $4074 \mathrm{~g}$ mol-1 and $5400 \mathrm{~g}$ mol-1 with polydispersity indices (PDI) of 1.192 and 1.267 respectively. With only one hour of thermal stabilization, the change in $\mathrm{M}_{\mathrm{n}}$ is distinguishable to confirm stabilization in the air at $180^{\circ} \mathrm{C}$ can be used to control the molecular weight of lignin. 

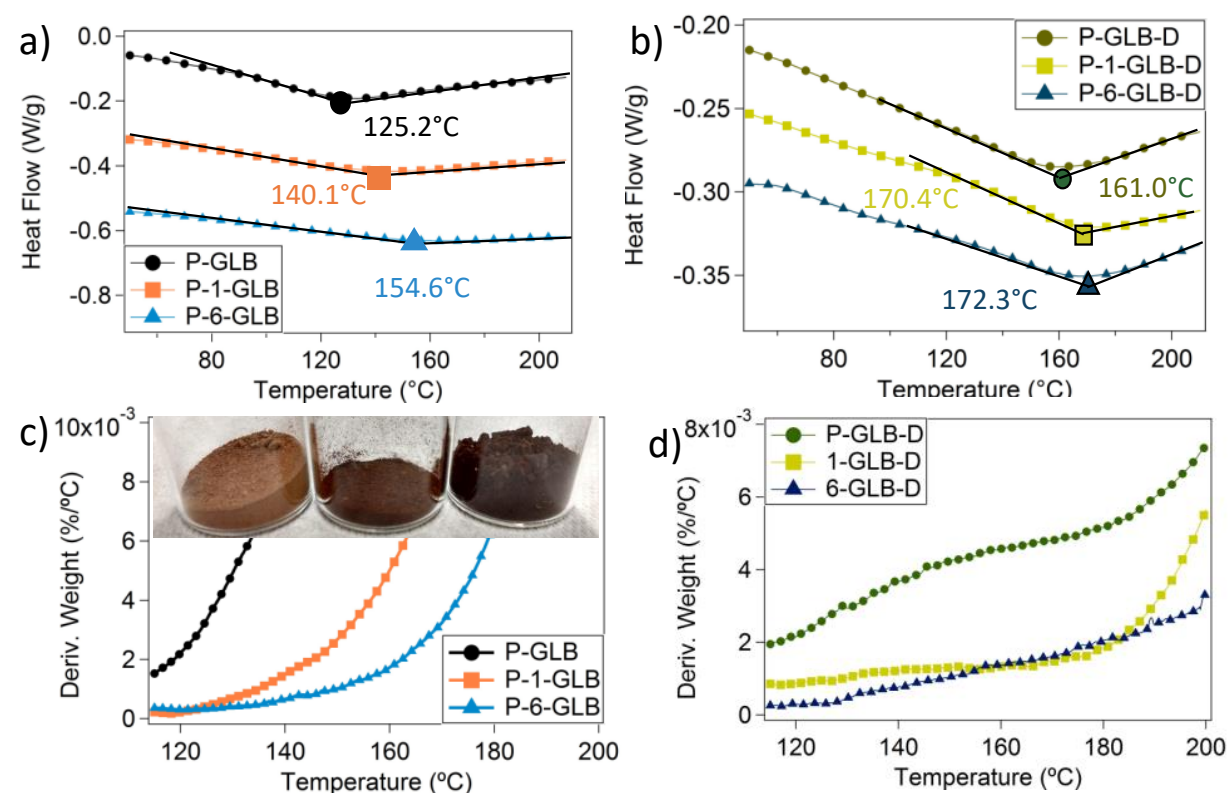

Figure 5. Thermal stability of carbon precursors with varied degree of crosslinking. Differential scanning calorimetry data of a) undoped GLB lignin carbon precursors and b) NBR doped GLB lignin carbon precursors showing broad glass transition temperatures (endset temperatures of the transitions are labeled in the Figures). Thermogravimetric analysis of c) undoped GLB lignin carbon precursors and d) NBR doped GLB lignin carbon precursors. The insert of c) is a photograph of all undoped GLB lignin carbon precursors. (From left to right: P-GLB, P-1-GLB, and 6-P-GLB)

To unveil the changes in the degree of crosslinking for the remaining samples, we approached other indirect methods. An increase in thermal stability can be an indication of crosslinking. ${ }^{[7]}$ However, we recognize that the presence of highly branched structures and certain degree of crosslinks within the samples considerably contributed to the broad thermal transitions and thus the thermal transition temperatures might be a crude determinant (Figure 6). Nevertheless, the endset temperatures determined from differential scanning calorimetry (DSC) showed an increasing trend from $125.2^{\circ} \mathrm{C}, 140.1{ }^{\circ} \mathrm{C}$, to $154.6^{\circ} \mathrm{C}$ for P-GLB, P-1-GLB, and P-6-GLB, respectively. Likewise, the endset temperatures of P-GLBD samples increased continuously from $161.0^{\circ} \mathrm{C}, 170.4^{\circ} \mathrm{C}$, to $172.3^{\circ} \mathrm{C}$ with no stabilization, one-hour stabilization and six-hours stabilization respectively. The DSC results clearly showed an obvious and expected trend of increasing polymer's degree of crosslinking with stabilization time (Figure 5a-b). Although less apparent with the doped samples, similar trends were also observed with the onset of thermal degradation as observed from the thermogravimetric analysis (TGA) in (Figure 5c-d). 

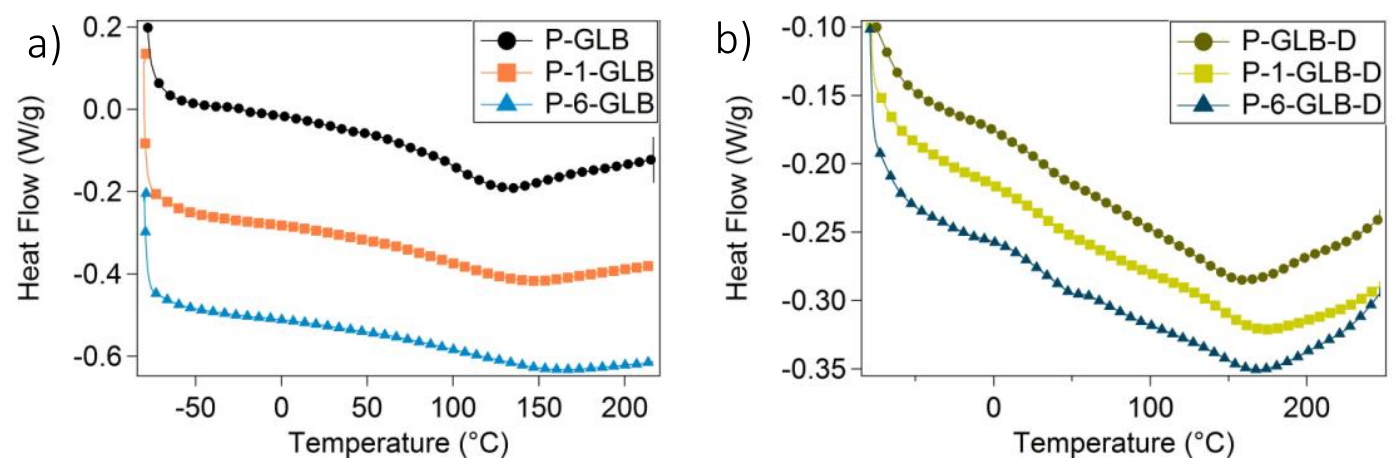

Figure 6. Differential scanning calorimetry data of a) undoped GLB lignin carbon precursors and b) NBR doped GLB lignin carbon precursors.

On par with DSC and TGA, we expected that crosslinking would cause a change with reactive functional groups in the carbon precursors as shown with Fourier-transform infrared spectra (Figure 7a-b). For undoped carbon precursor, a shift in alkene $(\mathrm{C}-\mathrm{H})$ bending frequency was detected from $835 \mathrm{~cm}-1$ and $770 \mathrm{~cm}-1$. The $(-\mathrm{O}-\mathrm{H})$ stretch with alcohol and carboxylic acid weakened with stabilization time at 3450 $\mathrm{cm}-1$. In turn, a stronger (-C-O-) stretch (e.g. ether and ester functional groups) was detected at $1170 \mathrm{~cm}-$ 1. In addition to a few changes in the undoped samples, FTIR spectra of all doped samples have peaks at ca. $970 \mathrm{~cm}-1$ due to the alkene $(-\mathrm{C}-\mathrm{H})$ bond and ca. $2350 \mathrm{~cm}-1$ due to the nitrile $(-\mathrm{C} \equiv \mathrm{N})$ stretch from NBR. Nonetheless, as stabilization progressed, the intensity of these peaks decreased as first or second order amine signal at $770 \mathrm{~cm}-1$ and carbonyl group at $1715 \mathrm{~cm}-1$ arose.
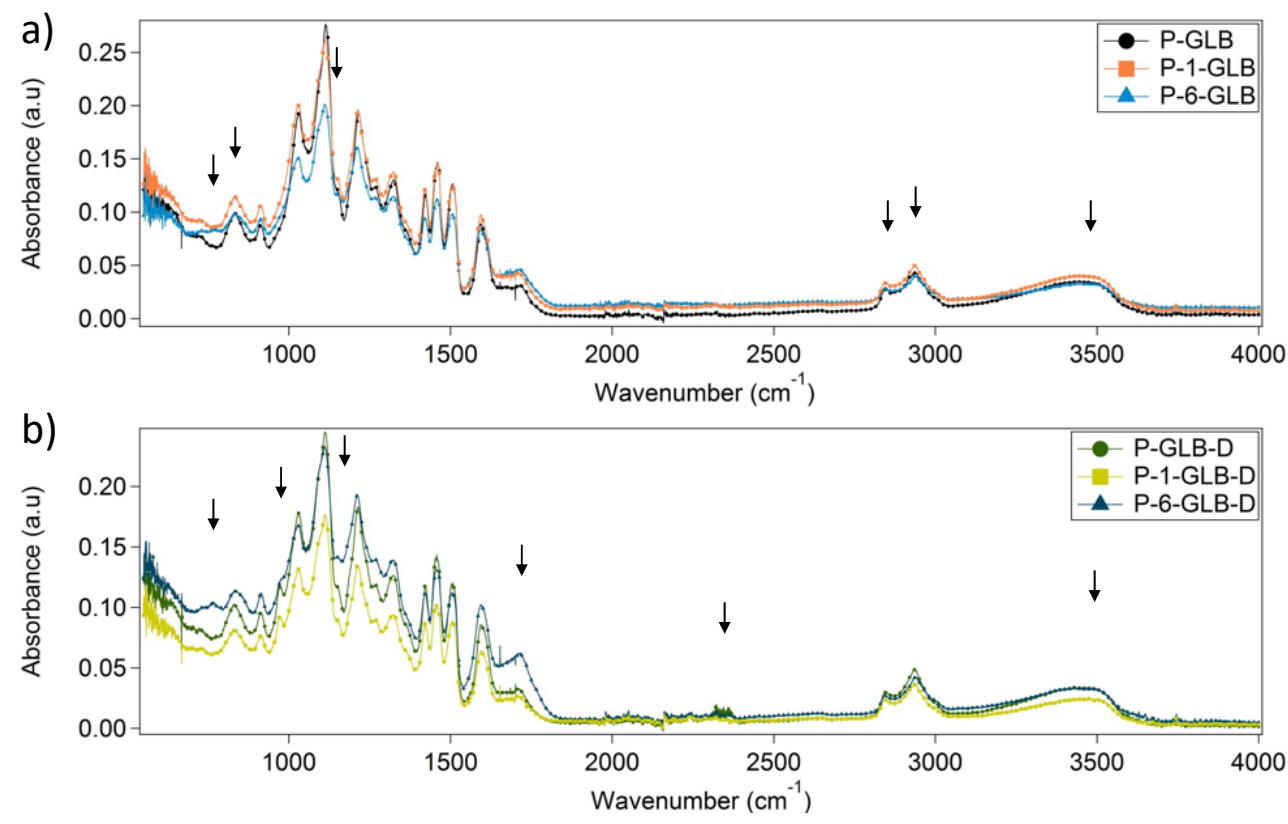

Figure 7. Chemical characteristics of carbon precursors with varied degree of crosslinking. Fourier-transform infrared spectroscopy of a) undoped GLB lignin carbon precursors and b) NBR doped GLB lignin carbon precursors. 
Gas adsorption-desorption experiments were then conducted with all carbon samples (Figure 8). All isotherms exhibit a steep initial climb at low relative pressure followed by a flat plateau, signifying typical type I isotherms with dominant microporosity (Figure 8a) ${ }^{[15]}$ All isotherms except for GLB and 1GLB also show small hysteresis, indicating capillary condensation in mesopores. ${ }^{[16]}$ Similar features can also be determined from the pore size distributions (Figure 8b). Both GLB and 1-GLB samples show a small but still distinct peak at ca. 2-3 nm in the pore-size distribution curve. Whereas, the other four samples show a contrastingly broader peak at ca. $3-5 \mathrm{~nm}$.
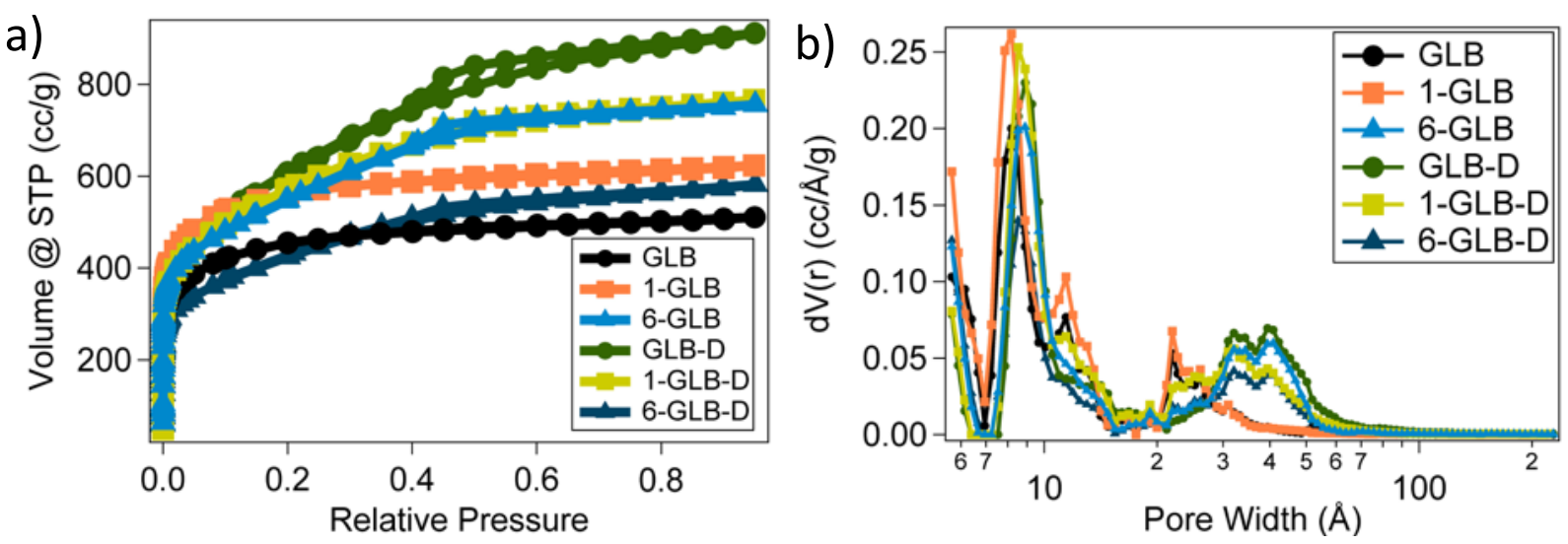

Figure 8. Gas adsorption-desorption data. a) Isotherms and b) pore-size distributions of all GLB lignin carbons.

The estimated surface area (SA) and corresponding pore volumes are calculated by Quenched Solid Density Functional Theory, QSDFT, and summarized in Table 2. Interesting trends were observed. When GLB lignin is doped with NBR prior to carbonization, the SA of the derived carbon increases from 1750 $\mathrm{m}^{2} / \mathrm{g}$ to $2120 \mathrm{~m}^{2} / \mathrm{g}$. However, when the doped GLB lignin is stabilized before carbonization, the SA of the derived carbon decreases continuously to $1912 \mathrm{~m}^{2} / \mathrm{g}$ with one-hour stabilization then $1585 \mathrm{~m}^{2} / \mathrm{g}$ with six hours of stabilization time. For undoped lignin, the SA first increases with stabilization time with 1-GLB giving $2136 \mathrm{~m}^{2} / \mathrm{g}$ but drops to $1970 \mathrm{~m}^{2} / \mathrm{g}$ with a six-hours stabilization time. The pore volume shows similar trends as well.

Table 2. Surface area, pore volumes, and capacitances at $100 \mathrm{~mA} / \mathrm{g}$ for all carbon samples.

\begin{tabular}{lccc} 
& $\begin{array}{c}\text { Surface area } \\
\left(\mathrm{m}^{2} / \mathrm{g}\right)\end{array}$ & $\begin{array}{c}\text { Pore Volume } \\
\left(\mathrm{m}^{3} / \mathrm{g}\right)\end{array}$ & $\begin{array}{c}\text { Capacitance } \\
(\mathrm{F} / \mathrm{g})\end{array}$ \\
\hline GLB & 1750 & 0.733 & 175 \\
1-GLB & 2136 & 0.893 & 201 \\
6-GLB & 1970 & 1.098 & 195 \\
GLB-D & 2120 & 1.33 & 215 \\
1-GLB-D & 1912 & 1.145 & 170 \\
6-GLB-D & 1585 & 0.845 & 154 \\
\hline
\end{tabular}


Many factors take part in controlling the final porosity of carbons. Jeon et al. recently revealed a significant contribution of precursor molecular weight to the carbon porosity. ${ }^{[4 b]}$ Briefly, low Mn lignin carbon precursor has more free volume, chain ends, and a higher chain mobility, allowing it to be carbonized more easily, leading to higher porosity relative to its higher Mn counterpart. ${ }^{[4 \mathrm{~b}, 14]}$ The difference in carbon precursor Mn directly relates to the degree of crosslinking as discussed previously in this manuscript with the FTIR, thermal stability, and color change of lignin and lignin-NBR composites in Figures 5 - 7.

The second major factor affecting carbon porosity can be volatile generations from the oxygen content of the carbon precursor. ${ }^{[4 \mathrm{~b}, 14]}$ Due to the possible oxidation of radicals, it is logical to suspect that stabilization altered the oxygen content of our carbon precursor. Thus, oxygen analysis was performed on all our carbon precursors. Interestingly, the change in oxygen content is minimal with respect to stabilization time (Table 3). Furthermore, potassium hydroxide $(\mathrm{KOH})$ is a well-known carbon activating agent. ${ }^{[4 a, 17]}$ During carbonization, $\mathrm{KOH}$ etches pores along carbon surfaces and at the same time provides ample supply of oxygen to the system, drowning out the small difference in oxygen content with the carbon precursors. $\mathrm{KOH}$ activation has been studied extensively and can be summarized as: ${ }^{[4]}$

$$
6 \mathrm{KOH}+2 \mathrm{C}=2 \mathrm{~K}+3 \mathrm{H} 2+2 \mathrm{~K} 2 \mathrm{CO} 3 .
$$

Table 3. Summary of oxygen analysis of all carbon precursor samples.

\begin{tabular}{lc}
\hline & Oxygen (\%) \\
\hline P-GLB & $29.13 \%$ \\
P-1-GLB & $29.28 \%$ \\
P-6-GLB & $29.16 \%$ \\
P-GLB-D & $25.61 \%$ \\
P-1-GLB-D & $25.91 \%$ \\
P-6-GLB-D & $26.59 \%$ \\
\hline
\end{tabular}

Another source of volatiles for the doped samples comes from the pyrolysis of NBR during carbonization. ${ }^{[18]}$ Thus far, lignin derived activated carbon's morphological control by thermal stabilization and melt-mixing of NBR in terms of porosity have been discussed in two scales and must be emphasized. We explored porosity in the micrometer scale in the beginning of the manuscript relating to the SEM images presented in Figure 4. Here, porosity in the nanometer scale is presented with the result from gas adsorption-desorption experiments relating to (Figures 8 and Table 2). NBR doping has a role to play in the development of both micrometer and nanometer size pores. We believe melt-mixing can be a rudimentary process. Porosity generated in the micrometer scale seen from Figure 4 may originate from the imperfect mixing of the $10 \%$ NBR aggregates within the lignin NBR composite. In contrast, the role of the $10 \%$ NBR dope here with the nanometer size porosity described by the gas adsorption-desorption originates from the well mixed NBR dispersion within the lignin matrix.

To understand the impact of carbon morphology on supercapacitor performance, we synthesized electrodes using our carbon samples and their electrochemical performance was tested. Supercapacitors, unlike Li-ion batteries, rely on the physical separation of charges for energy storage. ${ }^{[19]}$ Because physical 
charge separation is the key, a high performing supercapacitor correlates directly with the carbon electrode's porosity and accessible surfaces by electrode ions. ${ }^{[20]}$ The accessible pores are the active sites which allow electrode charges to interact with electrolyte ions, thus storing energy. As expected, the measured capacitance values largely correlate directly with SA of the carbon samples ${ }^{[21]}$ (Table 2). It is also anticipated that as current density increases, capacitance decreases, led by the limited rate of electrolyte diffusion through narrow pores relative to the increasing current (Figure 9a). ${ }^{[12]}$

Herein, GLB-lignin-derived electrodes have capacitances of up to 215 F/g with GLB-D. These performances are less than that of the cutting edge electrostatic-double-layer-capacitor (EDLC) electrodes fabricated using graphene or graphene-like materials with capacitances of ca. $300 \mathrm{~F} / \mathrm{g} .{ }^{[22]}$ However, those exotic carbon materials can cost three times more than the current commercial supercapacitor carbon electrodes made from coconut shell. ${ }^{[23]}$ In a supercapacitor where half of its material cost comes from the carbon electrode, ${ }^{[23]}$ a cost barrier can easily prevent market penetration, making a strong case for ligninderived carbon electrodes.

Cyclic voltammetry (CV) and charge discharge (CD) experiments were carried out (Figure 9b-c) with GLB-D as an example. Other CV and CD profiles are showed in (Figure 10-11). All CV and CD profiles exhibited almost symmetrical rectangular and triangular shapes respectively, suggesting excellent capacitive behaviors. Electrochemical impedance spectroscopy experiments were then conducted. The Nyquist plots of all samples (Figure 9d-e) behave like typical resistance-capacitance (R-C) circuits with nearly vertical lines at low frequency, suggesting near ideal capacitive behaviors. ${ }^{[24]}$ At a higher frequency, an arc shape with shallower slopes can be observed. The shallower slopes with ca. $45^{\circ}$ sitting in between the low and high frequencies signal Warburg resistance, stemming from electrolyte ions diffusion rate. ${ }^{[17]}$ The arcs at high frequency usually infer charge transfer resistance, which includes the accessibility of electrolyte ions onto porous carbon surfaces and the electrode's conductivity. Because the arcs did not extend into full semi-circles, they suggest minimal charge transfer resistance due to mainly larger pores taking parts in charge transfer ${ }^{[12]}$ The internal resistance, or equivalent series resistance, commonly known as ESR, which combines many aforementioned resistances and resistance of the carbon electrodes, bulk electrolytes, and any contact resistance, can be estimated from the X-intercepts. ${ }^{[25]}$ Estimated ESR ranged from $0.238 \Omega$ with 6-GLB sample to $0.466 \Omega$ with GLB sample (Table 4).

With these promising results, the two best performing samples along with GLB derived electrode were further tested with 5000 cycle stability (Figure 9f). All samples have high stability with $100 \%$ capacitance retention. The rise in capacitance during cycling can be a hint to the improvement of electrode wettability. ${ }^{[2]}$ The superior electrochemical stability and reversibility ${ }^{[27]}$ supports the use of NBR doping and thermal stabilization for a better lignin-derived carbon electrode design in practical supercapacitance applications. 

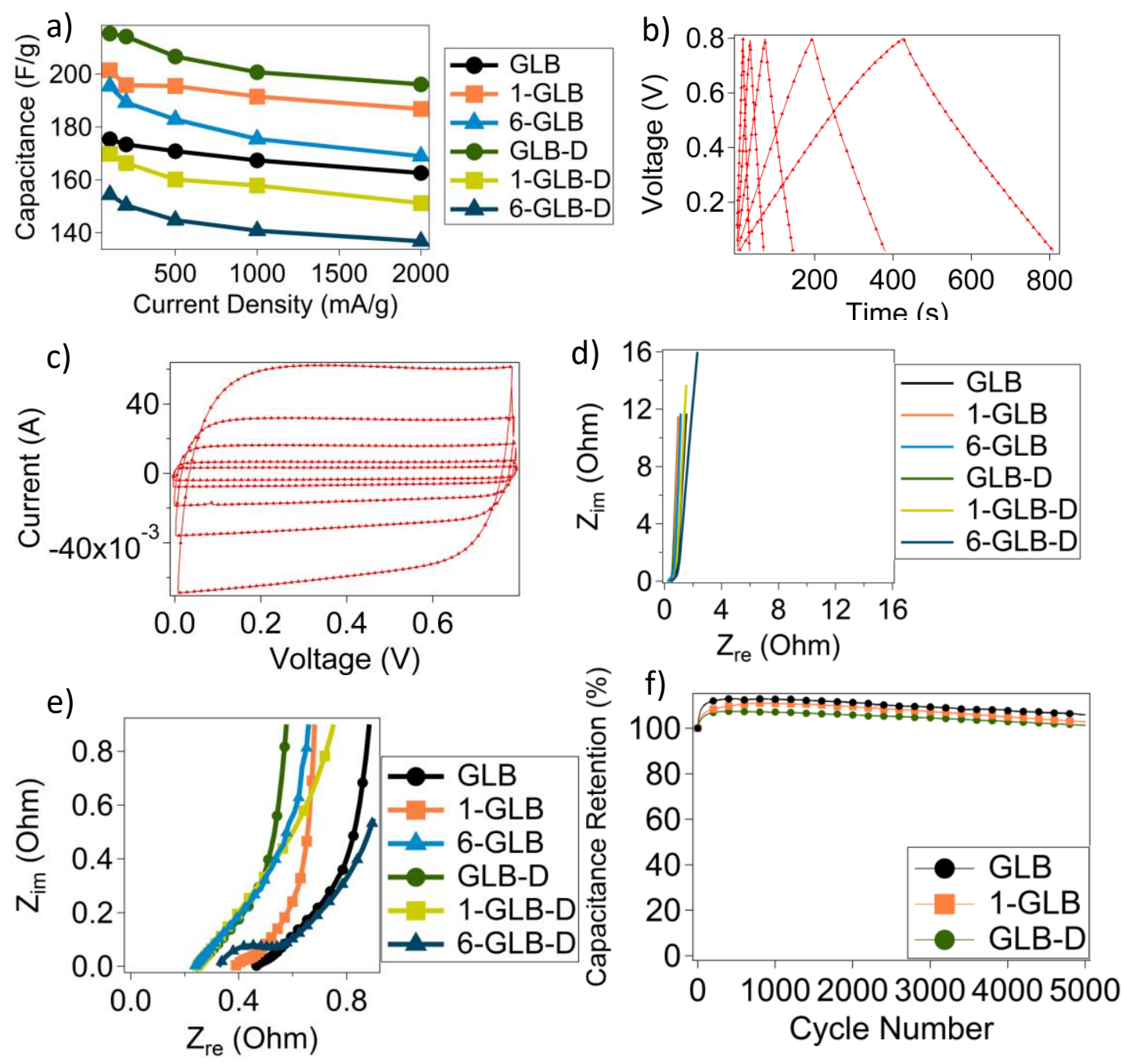

Figure 9. Performance of supercapacitor electrodes. a) Capacitance vs. current density of all samples. b) Typical charge discharge profiles at 100, 200, 500, 1000, and $2000 \mathrm{~mA} / \mathrm{g}$ and c) Typical cyclic voltammetry at 10,20,50,100, and $200 \mathrm{mV} / \mathrm{s}$ with doped GLB lignin-derived carbon as an example. d) Nyquist plots and e) enlarged Nyquist plots of all carbon electrodes. f) Cycle stability of GLB lignin derided carbon, doped GLB lignin-derived carbon, GLB lignin with one-hour stabilization-derived carbon. 

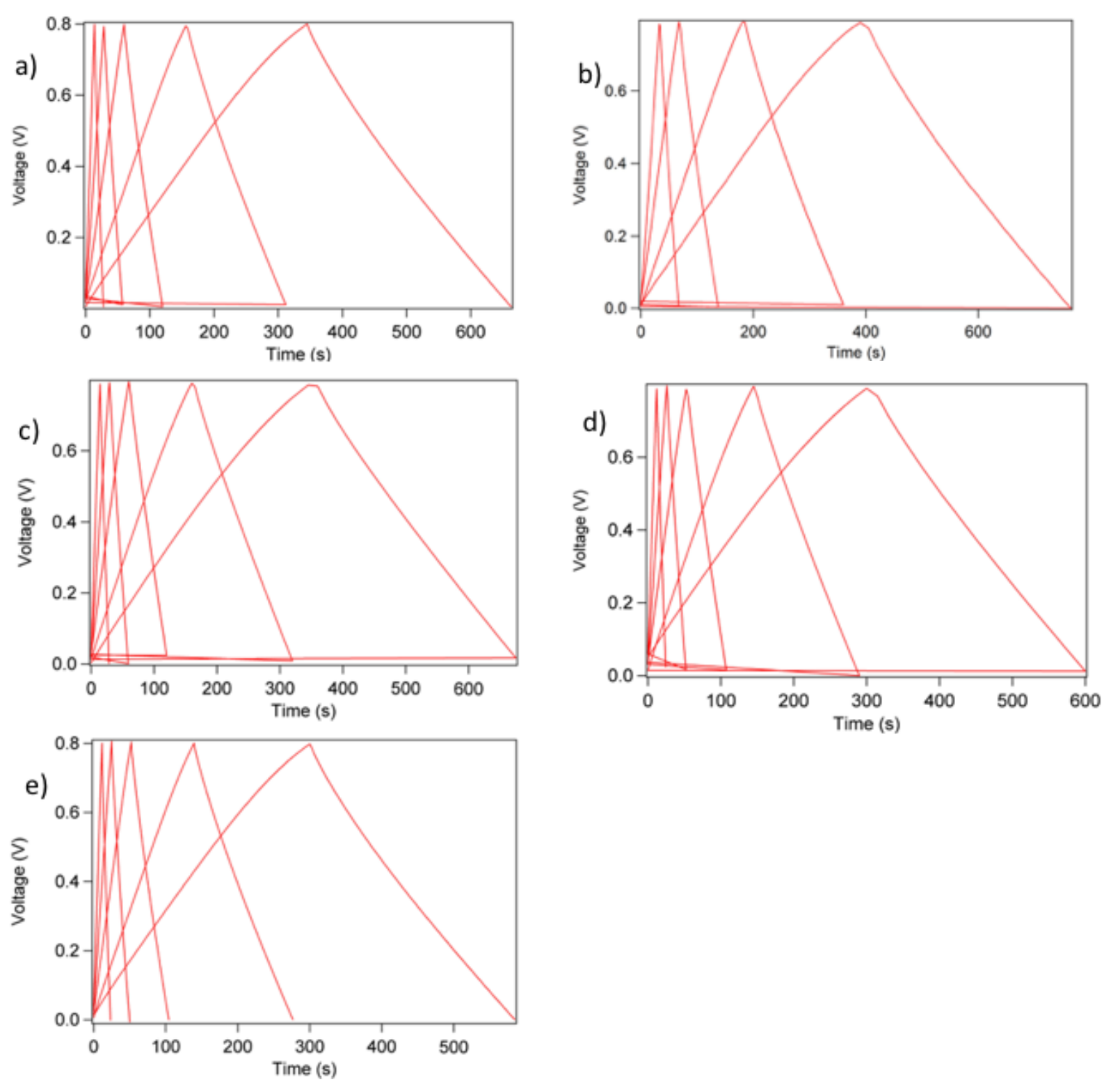

Figure 10. Charge discharge profiles at 100, 200, 500, 1000, and $2000 \mathrm{~mA} / \mathrm{g}$ of a) GLB ligninderived carbon, b) GLB lignin with one hour stabilization-derived carbon, c) GLB lignin with six hours stabilization-derived carbon, d) Doped GLB lignin with one hour stabilization-derived carbon, and e) Doped GLB lignin with six hour stabilization-derived carbon. 

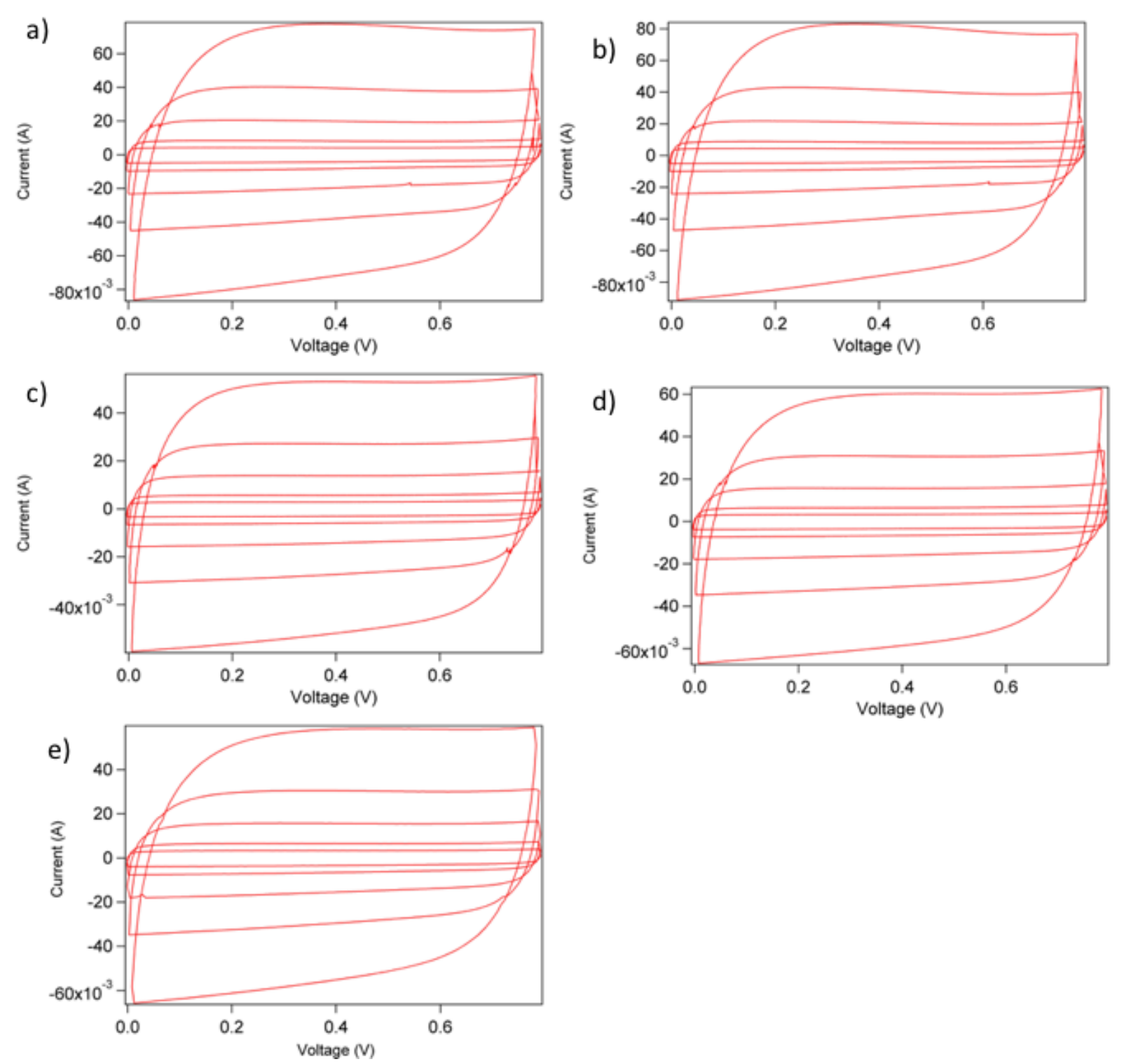

Figure 11. CV at 10, 20, 50, 100, and $200 \mathrm{mV} / \mathrm{s}$ of a) GLB lignin-derived carbon, b) GLB lignin with one hour stabilization-derived carbon, c) GLB lignin with six hours stabilization-derived carbon, d) Doped GLB lignin with one hour stabilization-derived carbon, and e) Doped GLB lignin with six hour stabilization-derived carbon. 
Table 4. Summary of internal resistances, or equivalent series resistances (ESR) of all carbon derived electrode samples.

\begin{tabular}{lc}
\hline & ESR $(\Omega)$ \\
\hline GLB & 0.466 \\
1-GLB & 0.384 \\
6-GLB & 0.238 \\
GLB-D & 0.247 \\
1-GLB-D & 0.247 \\
6-GLB-D & 0.324 \\
\hline
\end{tabular}




\section{SUBJECT INVENTIONS (AS DEFINED BY THE CRADA)}

A Solvent-Free Synthesis of Lignin-Derived Renewable Carbon with Tunable Porosity for Supercapacitor Electrodes, ORNL ID 4184 / DOE S-Number S-138,855.

\section{COMMERCIALIZATION POSSIBILITIES}

Glucan Biorenewables' overarching commercialization objective is to maximize biomass use to economically produce fuels, chemicals, and bio-materials. Our GVL-based biomass conversion platform enables a true bio-refining capability that shares traits with petroleum refining. In brief, a variety of biomass types (including mixes) are deconstructed and fractionated into intermediates that are further refined into products. Converting the entire "biomass barrel" to products decreases unit production costs by allocating total costs across an increased product volume. Within an integrated process, the biomass is separated into high purity streams of its three main components, cellulose, hemicellulose and lignin. This enables great flexibility in the chemicals and fuels produced and allows our technology to be coupled with other technologies to produce a large variety of renewable products. Because the economics to produce fuels at competitive costs $(<\$ 3.00 / \mathrm{GGE})$ are so challenging, valorizing all the biomass is essential.

As noted in our report, many workers have focused on the production of fuels and chemicals from the cellulose and hemicellulose biomass fractions. Getting revenue from the lignin beyond its heating value is both challenging and critical to enable the low-cost production of building block chemicals and fuels. This project indicates that GVL-derived lignin has physical characteristics that differentiate it from conventional lignin from pulp mills and even lignin derived from organosolv processing produced with low boiling point solvents such as ethanol. What differentiates the GVL-derived lignin is the reactive nature of the lignin through the retention of the $\beta-O-4$ linkages that are kept intact with a low severity (temperature and acid concentration) digestion process enabled by the high boiling point GVL solvent.

To valorize the lignin, we are seeking to use the lignin in processes requiring minimal modifications to the lignin and relatively low capital requirements to produce high value products with an existing or emerging market demand. Using the GVL-derived lignin as a pre-cursor for supercapacitor applications as discovered in this project is an excellent example of the type of commercial product we need to valorize the lignin.

As discussed, the GVL-derived lignin with $10 \%$ NBR doping produced electrodes with capacitances of up to $215 \mathrm{~F} / \mathrm{g}$. When comparing with the commercially available or similar state-of-the-art lignin and biomass derived supercapacitor electrodes (Table 5), our electrodes give a satisfying result. This performance is less than that of the cutting edge electrodes fabricated using graphene or graphene-like materials with capacitances of ca. $300 \mathrm{~F} / \mathrm{g} .{ }^{[22]}$ However, those exotic carbon materials can cost three times more than the current commercial supercapacitor carbon electrodes made from coconut shell at $\sim \$ 15$ per kilogram ${ }^{[23]}$ In a supercapacitor where half of its material cost comes from the carbon electrode, ${ }^{[23]}$ a cost barrier can easily prevent market penetration, making a strong case for lignin-derived carbon electrodes. Although more economic analysis will have to be performed to realize the feasibility for commercialization of this technology, the hardwood derived lignin produced with Glucan Biorenewables' GVL technology may represent an economically attractive alternative carbon material that is domestically sourced, equally renewable, and serves to enable economical biofuel production. 
Table 5. Performance summary of supercapacitor electrodes derived from commercial sources and the current state-of-the-art lignin and biomass research.

\begin{tabular}{ll}
\hline Capacitance $(\mathrm{F} / \mathrm{g})$ & Method \\
\hline 205 & PVA assisted lignin electrospun carbon fiber ${ }^{[28]}$ \\
103 & CO2 activated coffee grind \\
$90-103$ & KOH activated surfactant templated crosslinked lignin gel ${ }^{[12 \mathrm{a}]}$ \\
114 & Direct carbonization of lignin ${ }^{[4 \mathrm{~b}]}$ \\
210 & Commercial activated carbon, AX-2 ${ }^{[12 \mathrm{a}]}$ \\
90 & Commercial activated carbon, Wako $^{[29]}$ \\
\hline
\end{tabular}

\section{PLANS FOR FUTURE COLLABORATION}

Glucan Biorenewables aims to continue to provide lab-scale modified lignin samples ( $\sim 50 \mathrm{~g})$ to support further research and development and to work toward a minimum viable product sample for industry evaluation. We intend to jointly (ORNL and Glucan Biorenewables) pursue SBIR projects to continue the supercapacitor development. Strategic partners will be sought once we have adequate performance and cost of production data.

\section{CONCLUSIONS}

In summary, this work demonstrates a path for producing controlled morphology in activated functional carbon derived from a unique lignin developed by Glucan Biorenewables without the use of solvents and traditional templating agents. By simple thermal treatment of lignin carbon precursor in air at $180{ }^{\circ} \mathrm{C}$ for an optimal duration and/or melt mixing the lignin with $10 \mathrm{wt} . \% \mathrm{NBR}$, we were able to control the degree of crosslinking in the resulting polymeric blends. After carbonization and activation, the degree of crosslinking translated into carbon morphology and porosity, thus increased the SA from $1750 \mathrm{~m}^{2} / \mathrm{g}$ up to $2120 \mathrm{~m}^{2} / \mathrm{g}$. This design approach was also shown to be effective in tailoring lignin-derived carbon in supercapacitor electrode applications. The synthesized electrodes exhibited good capacitive behaviors with capacitance of up to $215 \mathrm{~F} / \mathrm{g}$ and full capacitance retention even after 5000 cycles. These, and others, new lignin applications will be critical for the development of the future biorefinery. While many works have focused on the production of fuel and chemicals from the cellulose and hemicellulose fraction, getting value from the lignin, beyond its heating value, will enable the low-cost production of building blocks chemicals and bio-fuels. 


\section{REFERENCES}

[1] H. C. Ho, M. Goswami, J. Chen, J. K. Keum, A. K. Naskar, Scientific Reports 2018, 8, 8355

[2] aS. Laurichesse, L. Avérous, Progress in Polymer Science 2014, 39, 1266-1290; bT. Saito, R. H. Brown, M. A. Hunt, D. L. Pickel, J. M. Pickel, J. M. Messman, F. S. Baker, M. Keller, A. K. Naskar, Green Chemistry 2012, 14, 3295-3303.

[3] D. M. Alonso, S. H. Hakim, S. Zhou, W. Won, O. Hosseinaei, J. Tao, V. Garcia-Negron, A. H. Motagamwala, M. A. Mellmer, K. Huang, C. J. Houtman, N. Labbe, D. P. Harper, C. Maravelias, T. Runge, J. A. Dumesic, Sci Adv 2017, 3, e1603301.

[4] aD. Saha, S. E. Van Bramer, G. Orkoulas, H.-C. Ho, J. Chen, D. K. Henley, Carbon 2017; bJ. W. Jeon, L. Zhang, J. L. Lutkenhaus, D. D. Laskar, J. P. Lemmon, D. Choi, M. I. Nandasiri, A. Hashmi, J. Xu, R. K. Motkuri, C. A. Fernandez, J. Liu, M. P. Tucker, P. B. McGrail, B. Yang, S. K. Nune, ChemSusChem 2015, 8, 428-432; cH. Li, D. Yuan, C. Tang, S. Wang, J. Sun, Z. Li, T. Tang, F. Wang, H. Gong, C. He, Carbon 2016, 100, 151-157; dW. Zhang, M. Zhao, R. Liu, X. Wang, H. Lin, Colloids and Surfaces A: Physicochemical and Engineering Aspects 2015, 484, 518-527; eW. Zhang, H. Lin, Z. Lin, J. Yin, H. Lu, D. Liu, M. Zhao, ChemSusChem 2015, 8, 2114-2122.

[5] aS. M. Kang, X. H. Li, J. Fan, J. Chang, Industrial \& Engineering Chemistry Research 2012, 51, 9023-9031; bT. Shimada, T. Hata, M. Kijima, Acs Sustainable Chemistry \& Engineering 2015, 3, 1690-1695; cG. Chieffi, N. Fechler, D. Esposito, Rsc Advances 2015, 5, 63691-63696.

[6] V. P. Saraf, W. G. Glasser, Journal of applied polymer science 1984, 29, 1831-1841.

[7] N. A. Nguyen, K. M. Meek, C. C. Bowland, S. H. Barnes, A. K. Naskar, Macromolecules 2017.

[8] J. Braun, K. Holtman, J. Kadla, Carbon 2005, 43, 385-394.

[9] W. Thielemans, R. P. Wool, Biomacromolecules 2005, 6, 1895-1905.

[10] Q. N. Sun, R. Khunsupat, K. Akato, J. M. Tao, N. Labbe, N. C. Gallego, J. J. Bozell, T. G. Rials, G. A. Tuskan, T. J. Tschaplinski, A. K. Naskar, Y. Q. Pu, A. J. Ragauskas, Green Chemistry 2016, 18, 5015-5024.

[11] C. D. Tran, J. Chen, J. K. Keum, A. K. Naskar, Advanced Functional Materials 2016, 26, 2677-2685.

[12] a)D. Saha, Y. Li, Z. Bi, J. Chen, J. K. Keum, D. K. Hensley, H. A. Grappe, H. M. Meyer, 3rd, S. Dai, M. P. Paranthaman, A. K. Naskar, Langmuir 2014, 30, 900-910; b) C. D. Liang, S. Dai , Chem. Mater. 2009, 21, 2115-2124.

[13] aK. Akato, C. D. Tran, J. H. Chen, A. K. Naskar, Acs Sustainable Chemistry \& Engineering 2015, 3, 3070-3076; bT. Bova, C. D. Tran, M. Y. Balakshin, J. Chen, E. A. Capanema, A. K. Naskar, Green Chemistry 2016, 18, 5423-5437.

[14] S. Chatterjee, T. Saito, ChemSusChem 2015, 8, 3941-3958.

[15] D. Saha, G. Orkoulas, S. Yohannan, H. C. Ho, E. Cakmak, J. Chen, S. Ozcan, ACS Applied Materials \& Interfaces 2017, 9, $14506-14517$.

[16] M. Thommes, K. Kaneko, A. V. Neimark, J. P. Olivier, F. Rodriguez-Reinoso, J. Rouquerol, K. S. Sing, Pure and Applied Chemistry 2015, 87, 1051-1069.

[17] C. D. Tran, H. C. Ho, J. K. Keum, J. Chen, N. C. Gallego, A. K. Naskar, Energy Technology 2017.

[18] A. K. Naskar, Z. H. Bi, Y. C. Li, S. K. Akato, D. Saha, M. F. Chi, C. A. Bridges, M. P. Paranthaman, Rsc Advances 2014, 4, 38213-38221.

[19] P. Simon, Y. Gogotsi, Nat Mater 2008, 7, 845-854.

[20] J. Chmiola, G. Yushin, Y. Gogotsi, C. Portet, P. Simon, P. L. Taberna, Science 2006, 313, 1760-1763.

[21] E. Raymundo-Piñero, M. Cadek, F. Béguin, Advanced Functional Materials 2009, 19, 1032-1039.

[22] aW. Q. Tian, Q. M. Gao, L. M. Zhang, C. X. Yang, Z. Y. Li, Y. L. Tan, W. W. Qian, H. Zhang, Journal of Materials Chemistry A 2016, 4, 86908699; bY. Xu, Z. Lin, X. Zhong, X. Huang, N. O. Weiss, Y. Huang, X. Duan, Nat Commun 2014, 5, 4554.

[23] L. Weinstein, R. Dash, Materials Today 2013, 16.

[24] J. Liu, X. Wang, J. Gao, Y. Zhang, Q. Lu, M. Liu, Electrochimica Acta 2016, 211, 183-192.

[25] M. D. Stoller, R. S. Ruoff, Energy \& Environmental Science 2010, 3, 1294-1301.

[26] H. Peng, G. Ma, K. Sun, J. Mu, Z. Zhang, Z. Lei, ACS applied materials \& interfaces 2014, 6, 20795-20803.

[27] Z. Fan, Y. Liu, J. Yan, G. Ning, Q. Wang, T. Wei, L. Zhi, F. Wei, Advanced Energy Materials 2012, 2, 419-42

[28] M. Ago, M. Borghei, J. S. Haataja, O. J. Rojas, RSC Advances 2016, 6, 85802-85810.

[29] D. Tashima, Y. Hamasuna, D. Mishima, S. Kumagai, J. D. Madden, IEEJ Transactions on Electrical and Electronic Engineering 2014, 9 , 343350. 